\title{
Synthesis and Characteristics of Local Fly Ash Based Geopolymers Mixed with Natural Aggregates
}

\author{
DUMITRU DORU BURDUHOS NERGIS'1, PETRICA VIZUREANU1,4*, OFELIA CORBU2,3,4 \\ ${ }^{1}$ Gheorghe Asachi Technical University of lasi, Faculty of Materials Science and Engineering, 67 D. Mangeron Str., 700050, Iasi, \\ Romania \\ ${ }^{2}$ Technical University of Cluj-Napoca, Faculty of Civil Engineering, 28 Memorandumului Str.,400114, Cluj-Napoca, Romania \\ ${ }^{3}$ Research Institute for Construction Equipment and Technology, ICECON SA Bucuresti, 266 Pantelimon Road, 021652, Bucharest, \\ Romania \\ ${ }^{4}$ Center of Excellence Geopolymer \& Green Technology (CEGeoGTech), School of Materials Engineering, Universiti Malaysia \\ Perlis, 01000 Kangar, Perlis, Malaysia
}

\begin{abstract}
Global industrialization generates large amount of waste which strongly affects the depositing areas and the living creatures from the surroundings. In the same time, the construction sector meets an exponential development process, resulting in materials and construction areas increase. Therefore, the need of new materials was felt worldwide. One solution that knew a rapid development, especially in this sector, was to obtain new eco-friendly materials through a mechanism called geopolymerization. True this powerful chemical reaction between a waste, rich in aluminum and silicon, and a strong alkaline solution, a tetragonal structure of Al-O-Si is obtained that possess properties comparable to those of Portland cement-based concrete. In the present paper the effect of aggregates on local fly ash based geopolymers is analyzed from the structure and mechanical properties point of view. According to this study, the aggregates strongly influence the density, compression strength and flexural strength at any age of samples.
\end{abstract}

Keywords: geopolymers, local fly ash, aggregates, physical and mechanical characteristics

The large waste volume generated in thus days represents a serious problem for the environment as well as for the population living near storage areas of these technological processes by-products. Another problem associated with the obtaining of ceramic materials, mainly of Portland cement concrete, is related to non-renewable raw materials exploitation which also involve high energy consumption. The $10 \mathrm{~km}^{3} /$ year production place concrete on the first place as the most used material on Earth [1]. Thus, in order to reduce the consumption of raw materials and economic resources, in recent years, the re-use of materials has been emphasized on a global scale [2]. A simple technique, known as geopolymerization [3], grows in interest in obtaining building materials with properties similar to those based on Portland cement, but using waste as raw material [4]. The final product obtained through geopolymerization is called geopolymer, which can be described as totally inorganic ceramic material based on aluminum and silicone compounds (table 1) [5].

Materials used in the building industry [6], in particular at insulating fire-bricks used for reheat furnaces, must possess specific characteristics such as high refractoriness, high compressive and corrosion resistance, high hardness and resilience, low density etc. Currently, the classical ceramic materials used in the field of construction are: Portland cement concrete, siliceous refractory mortars, silico-alumina refractory mortars, magnesite mortars etc. Some of these materials present multiple disadvantages related to obtaining methods, properties (resistance to compression over time, corrosion resistance, resistance to freeze-thaw cycles) or environmental impact, therefore the last decade research in the construction materials field have been focused on improving the properties and the production methods [7]. By using waste as raw material, by geopolymerization means, we can obtain ecofriendly materials with even better properties [8].

The alumino-silicate minerals are going through multiple stages during geopolymerization process, firstly the raw material is dissolved under alkaline condition followed by speciation equilibrium, gelation and reorganization and secondly the polymerization processes take place resulting a tetrahedral network of Si-O-Al which combines 0 atoms to form polysialate, polysialate-siloxo or polysialate-disiloxo molecules, depending on the $\mathrm{SiO}_{2} / \mathrm{Al}_{2} \mathrm{O}_{3}$ ration in the system, as follows:

$$
\mathrm{Na}_{\mathrm{x}} \cdot\left[-\left(\mathrm{SiO}_{2}\right)_{\mathrm{y}}-\mathrm{AlO}_{2}\right] \cdot\left(\mathrm{H}_{2}\right)_{z}
$$

where: $\mathrm{Na}=$ the alkaline element (sodium in this study) [10].

Table 1

POLYSIALATE TYPES PRESENT IN GEOPOLYMERS [9]

\begin{tabular}{|c|c|c|c|}
\hline $\begin{array}{c}\text { Polysialate } \\
\text { Si:A1 = } 1 \\
(-\mathrm{Si}-\mathrm{O}-\mathrm{Al} 1-\mathrm{O})\end{array}$ & 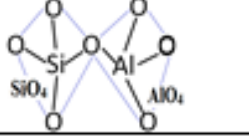 & $\begin{array}{c}\text { Polysialate -disiloxo } \\
\text { Si:A1 = } 3 \\
\text { (-Si-O-Al-O-Si-O-Si-O-) }\end{array}$ & 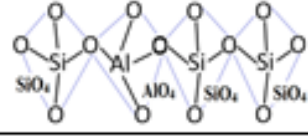 \\
\hline $\begin{array}{c}\text { Polysialate-siloxo } \\
\text { Si:A1 = } 2 \\
(-\mathrm{Si}-\mathrm{O}-\mathrm{Al}-\mathrm{O}-\mathrm{Si}-\mathrm{O}-)\end{array}$ & 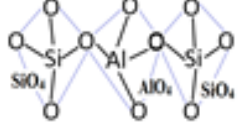 & $\begin{array}{c}\text { Sialate bond } \\
\text { Si:Al }>3\end{array}$ & \\
\hline
\end{tabular}




\section{Experimental part}

Materials and methods

Geopolymers structure

Any geopolymer can be divided in two main constituents, the base material and the activator (an alkaline liquid). The major constituent is the basic material, itmust be rich in silicon and aluminum and can be a natural mineral, such as: clay, kaolin etc. or waste, such as: fly ash, red mud, slags etc. Cost, availability or the necessary specification of the final material are just few of the factors that can influence the choice of basic material for a geopolymer [11]. The second component, the liquid, which must be selected in accordance with the raw material chemical composition, is based on soluble alkali metals usually of sodium or potassium [12].

After mixing thus components, the process is followed by a curing stage, which can take place at low $\left(20^{\circ} \mathrm{C}\right)$ or slightly high temperature $\left(70-80^{\circ} \mathrm{C}\right)$. In other words, the formation of geopolymers involves mixing a liquid with a solid as is described in figure 1.

Due to the fact that mainly any material rich in aluminum and silicon, which can be dissolved by an alkaline solution, can be used for geopolymers, a number of wastes have been identified globally with potential for geopolymerization, such as: furnace ash [13, 14], red mud [15], blast furnace slag [16] etc. After the chemical reaction between the solid component, the waste, and the alkaline activator, a solution of sodium silicate and sodium hydroxide, a totally inorganic material with a similar structure to the zeolite is obtained.
In this study a series of alkali-activated fly ash based geopolymers samples were studied from the structural and mechanical point of view.

\section{Flyash}

Fly ash is a by-product derived from coal combustion in power plants. During burning of coal in combustion chambers, some volatile materials are produced. With the cooling of the exhaust gases, the fused materials solidify into glass spheres called fly ash. Due to the fusion-in-suspension fly ash particles are generally solid torque spheres, as presented in figure 2 .

The performance of fly ash in geopolymers is strongly influenced by its physical, chemical and mineralogical properties. The mineralogical and chemical composition (table 2) depends mainly of coal composition. Another parameter important in fly ash based geopolymers is raw material particle size, according to other studies smaller particles result in higher properties, this study analyze the properties of geopolymers made with fly ash smaller than 80 $\mu \mathrm{m}$.

According to the ASTM C618-92a standard, the local fly ash belongs to class $\mathrm{F}$ by having the sum of silicone, aluminum and iron oxides over $70 \%$ (eq.1).

\section{Aggregates}

$$
\begin{aligned}
\mathrm{SiO}_{2}+\mathrm{Al}_{2} \mathrm{O}_{3}+\mathrm{Fe}_{2} \mathrm{O}_{3} & =47.8 \%+28.6 \%+ \\
+ & +10.2 \%=86.6 \%
\end{aligned}
$$

In order to increase the mechanical properties of geopolymers, different type or quantities of aggregates can be added in the composition. Aggregates particle size distribution (table 3 ) can also affect the sample homogeneity or porosity.
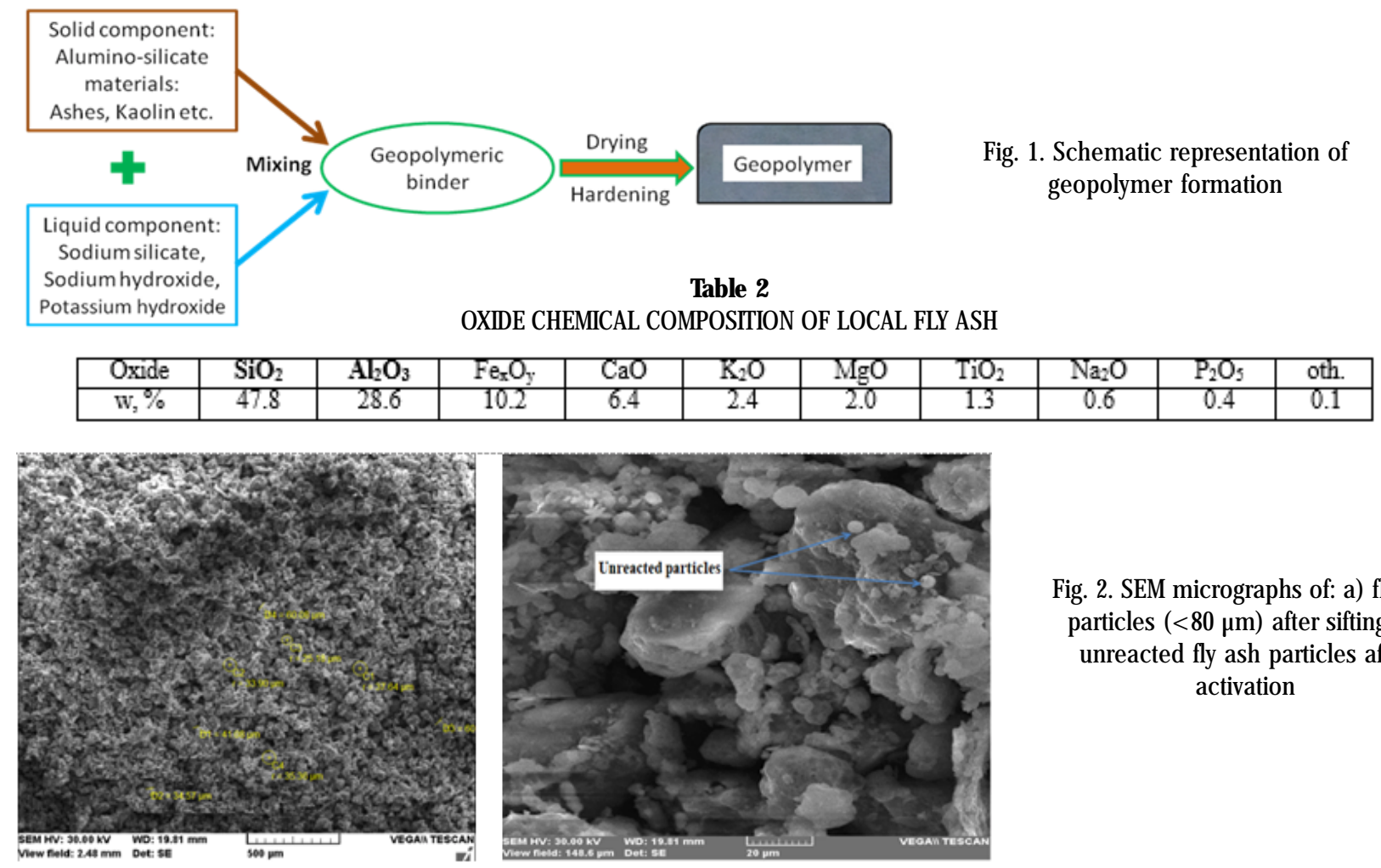

Fig. 2. SEM micrographs of: a) fly ash particles (<80 $\mu \mathrm{m})$ after sifting; b) unreacted fly ash particles after activation

\begin{tabular}{|c|c|c|c|c|}
\hline Sieves & $\begin{array}{c}\text { Diameter } \\
(\mathrm{mm})\end{array}$ & $\begin{array}{c}\text { Sample weight } \\
\mathbf{g}\end{array}$ & $\begin{array}{c}\text { Retained } \\
\%\end{array}$ & $\begin{array}{c}\text { Pass } \\
\%\end{array}$ \\
\hline 1 & $\mathbf{4 . 0 0 0}$ & $\mathbf{0}$ & $0.00 \%$ & $100.00 \%$ \\
\hline 2 & $\mathbf{3 . 7 5 0}$ & $\mathbf{1 0 . 9}$ & $10.90 \%$ & $89.10 \%$ \\
\hline 3 & $\mathbf{2 . 0 0 0}$ & $\mathbf{1 4 . 0}$ & $14.00 \%$ & $75.10 \%$ \\
\hline 4 & $\mathbf{0 . 2 1 0}$ & $\mathbf{1 8 . 7}$ & $18.70 \%$ & $56.40 \%$ \\
\hline 5 & $\mathbf{0 . 1 2 5}$ & $\mathbf{3 6 . 7}$ & $36.70 \%$ & $19.70 \%$ \\
\hline Dish & $\mathbf{0}$ & $\mathbf{1 9 . 7}$ & $19.70 \%$ & $0.00 \%$ \\
\hline
\end{tabular}

Table 3

PARTICLE SIZE DISTRIBUTION OF AGGREGATES 


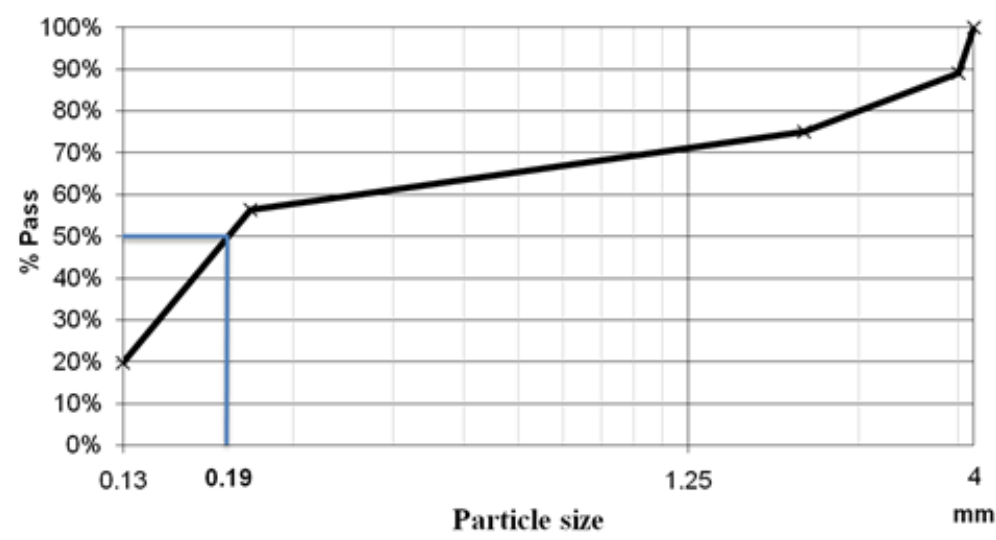

Prior sifting the aggregates were dried in order to reduce the measurement errors due to the bonding of fine sand particles or their adhesion to the sieves surface. Figure 3 presents the granulometric distribution chart and d50 of used aggregates, according to the graph the material contains a small number of large particles, only $30 \%$ over $1.25 \mathrm{~mm}$.

\section{Activator}

Sodium silicate solution is manufactured by fusing sand $\left(\mathrm{SiO}_{2}\right)$ with sodium carbonate $\left(\mathrm{Na}_{2} \mathrm{CO}_{3}\right)$ at high temperatures. Sodium silicate is rarely used as an independent activator, as it does not possess an activation potential sufficiently high to initiate the puzzolone reaction, it is usually mixed with $\mathrm{NaOH}$ as an enhancing agent to improve alkalinity and to increase the overall resistance of specimens.

The presence of sodium silicate, also improves the bonding relationship between the aggregate and the geopolymeric mortar. $\mathrm{NaOH}$ solutions is mainly used for alkalinity, in general the dissolution of the material is stronger as the concentration of the alkaline solution increases. The dissolution capacity of activator solution usually influences the final properties of geopolymers.

The activating solution used in this study consist in a mix of two components, a commercial sodium silicate solution with $\mathrm{pH}<11.5 \%$, density of $1.37 \mathrm{~g} / \mathrm{cm}^{3}$, molarities of 122 and low copper, lead and nickel content ( $\max 0.005$ $\%)$ and high purity (97\%) sodium hydroxide flakes dissolved in water $24 \mathrm{~h}$ prior to mixing to the desired molar concentration (10 M). The most used alkaline liquid used for geopolymerization is a combination of sodium hydroxide and sodium silicate.

\section{Sample preparation}

The production process consists in the preparation of the solid and the liquid components, as follows: the fly ash is dried, sieved (only particles smaller than $80 \mu \mathrm{m}$ were used) and mixed or not with $70 \%$ by mass aggregates, the sodium hydroxide flakes are dissolved in water at the desired molar concentration $(10 \mathrm{M}, 31.4 \% \mathrm{NaOH}$ and $68.6 \%$ water) and mixed at 1.5 ratio (eq. 2) with sodium silicate after $24 \mathrm{~h}$. Thus 4 compounds are mixed together at 1.5 ratio (eq. 3) in a stainless steel vessel with a low speed mixer for $10 \mathrm{~min}$. The geopolymeric paste is poured into the mold, subjected to vibration and heat treated. The sample composition is presented in table 4.

Fig. 3. Particle size distribution of aggregates

$\frac{\text { g sodium silicate solution }}{\text { g sodium hydroxide solution } 10 \mathrm{M}}=\mathbf{1 . 5}$

g solid (fly ash)

$\overline{\text { g activator solution (sodium silicate + sodium hydroxide) }}$

Due to the spherical shape of fly ash particles, which implies a lower frictional force between them, the final properties of the material are influenced by the mixture workability. The mixing stage and the solid to liquid ratio affects the geopolymerization reaction, low geopolymeric paste workability can lead to compaction difficulties followed by a porous and weak final structure [17].

\section{Hardening treatment}

Heat treatment setting time and temperature of samples has a direct effect on the compressive and flexural strength Thus, properties can be positively influenced by keeping samples at room temperature for a long period of time before being subjected to high temperatures. Thermal treatment temperature and holding time are the most important factors at this stage, too high temperatures will lead to fast and forced water evaporation that will create a large number of cracks and will reduce the dissolution capacity of the alkaline activator. Too long holding time or a too low temperature will produce minimal effects on the properties. In this study the curing temperature used was $70 \mathrm{C}$ for an $8 \mathrm{~h}$ holding time.

In addition to adjusting the chemical activator and the curing regime, the type and characteristics of solid component play an essential role in the development of the mechanical properties, durability and microstructure. In general, fine particle pastes will present superior mechanical properties and dense microstructures.

\section{Mechanical properties}

In order to study the mechanical properties of the geopolymer samples the specific structure must be considered (porous material with high defects concentration near the matrix-aggregate interface area). As it is specific to fragile materials, the geopolymers samples breakage process passes through three phases:

-crack initiation;

- crack propagation;

-the growth and development of cracks.

In ceramic materials, the cracks do not propagate in a straight line, but follow a sinuous direction around the

\begin{tabular}{|c|c|c|}
\hline Sample components & Fly ash mix sample & $\begin{array}{c}\text { Fly ash and aggregates } \\
\text { mix sample }\end{array}$ \\
\hline Fly ash $<80 \mu \mathrm{m}$ & $100 \%$ & $30 \%$ \\
\hline Aggregates $<100 \mu \mathrm{m}$ & $0 \%$ & $70 \%$ \\
\hline Sodium silicate solution & $66 \%$ & $66 \%$ \\
\hline Sodium hydroxide solution (10M) & $44 \%$ & $44 \%$ \\
\hline
\end{tabular}

Table 4

SAMPLES COMPOSITION 
aggregates or around the different phases of the cement stone. Aggregates or pores can block or deviate the cracks.

Compressive strength is one of the main criteria of checking the quality of a geopolymer sample [17]. The value obtain depends on the test conditions, the shape and sample dimensions, manufacturing and storage condition, loading speed etc. Because of friction between sample surfaces and plates tangential stresses occur at the geopolymer-metal separation limit, which prevents the sample cross-sectional deformations, increasing their strength. The specimen destruction is produced by detaching its lateral sides after inclined planes at about $30^{\circ}$ to the vertical (fig. 4). Cracks formation can be also observed in the load/displacement graphs as it is shown in figure 5.

There are multiple standards that specify the test methods of mechanical properties determination of geopolymeric samples. In this study C109/C 109M-07 Standard test method for compressive strength of hydraulic cement mortars have been complied.
Flexural strength can be tested by applying a force in the center point on the upper surface of a sample when the lower surface is placed on two supports (fig. 6). where: $\mathrm{F}$ - load, kN; I - distance between equipment supports, $\mathrm{mm}$.

Except the sample dimensions and shape, flexural strength is influenced by the same factors as compression strength.

\section{Results and discussions}

Microstructural analysis

There are multiple factors related to the geopolymer final structure, alkaline solution concentration influences the pores sizes and distribution, also inappropriate mixing can result in a heterogeneous sample.

Geopolymer samples microstructure and chemical composition has been analyzed by SEM and EDS means. In order to obtain a clear image of the samples structure, the surface was coated with a thin layer of conductive carbon.
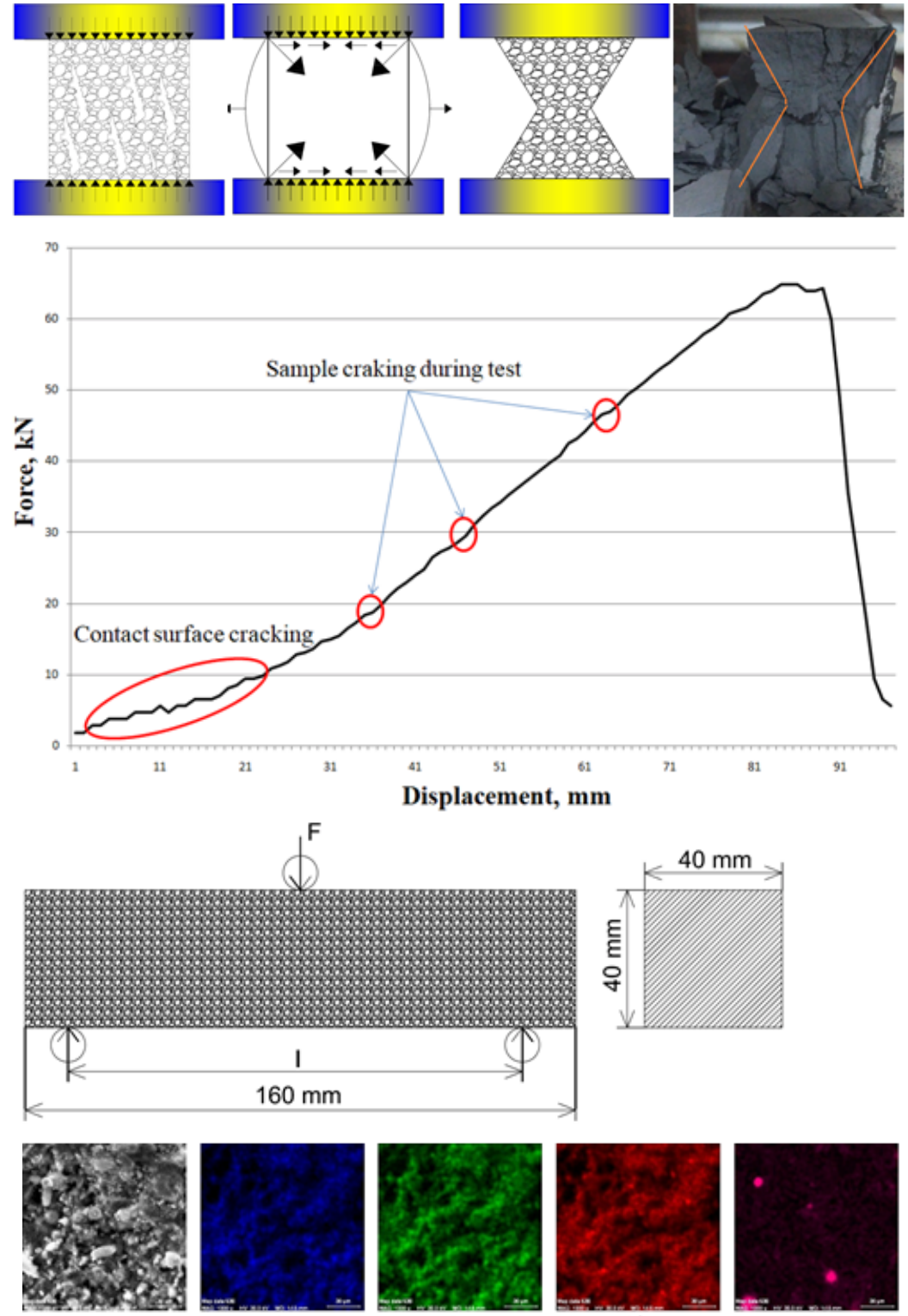

$\mathrm{Na}$

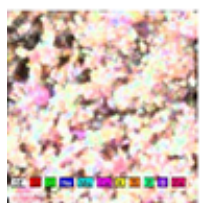

All

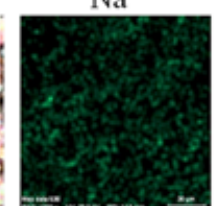

$\mathrm{Al}$

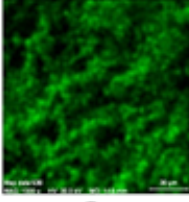

$\mathrm{O}$

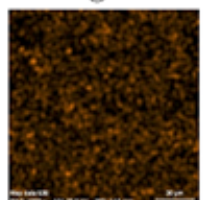

$\mathrm{Ti}$

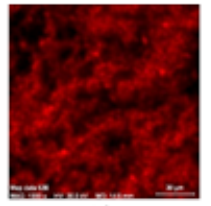

$\mathrm{Si}$

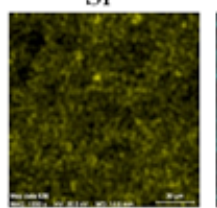

$\mathrm{K}$
Fig. 4. Breaking behavior of geopolymer specimens in the frictional compression test between plates and the sample

Fig. 5. Load/displacement graphs of geopolymer samples

Fig. 6. Schematic representation of center point loading of flexural strength test 
Following the samples solidification by exposing at 70 ${ }^{\circ} \mathrm{C}$ temperature, the samples present homogeneous chemical composition (fig. 7), mainly natrium, aluminum and oxygen (fig. 8), however, in the upper side it can be observed a $3 \mathrm{~mm}$ thickness layer of different color. This layer also presents a different chemical composition and can be related with the density difference between the solid and the liquid component, as well as the fly ash impurities. The entire surface presents cracks, unreacted fly ash particles and a half sphere pattern related to air bubbles evacuation during curing time, as it is shown in figure 8 .

At $100 \times$ SEM micrographs (fig. 10) samples present different pores distribution and structure. Fly ash sample (fig. 10: a)) present multiple unreacted particles, few cracks which can be related to the compressive test previously performed and low number of pores. Atthe same magnitude in fly ash and aggregates samples (fig. 10: b)) can be observed a much better dissolved and serried structure with high number of pores blocked inside the sample by the aggregates, being harder to remove during sample vibrating stage.

As it is shown in figure 11during mechanical tests cracks have advanced through the interface between matrices and aggregates (fig. 11a), meaning that from the compressive strength point of view the matrix is weaker than the aggregates.

In case of fly ash samples (fig. 11b) the cracks advanced through the areas where the number of unreacted particles is the highest.

If low density geopolymers are requested, 100 fly ash geopolymers are ideal having a density of just $1.2 \mathrm{~g} / \mathrm{cm}^{3}$, by replacing fly ash with aggregates in $70 \%$ by mass density is increased to roughly $1.8 \mathrm{~g} / \mathrm{cm}^{3}$.

\section{Mechanical properties}

Compressive strength test has been performed according to C109/C 109M-07 - Standard test method for compressive strength of hydraulic cement mortars on a minimum batch of 5 samples with 50 . $5050 \mathrm{~mm}$ dimensions, at $4 \mathrm{~mm} / \mathrm{s}$ punch speed. Replacing fly ash with aggregates in $70 \%$ by mass increases the compressive strength from 7.54 MPa to $12.36 \mathrm{MPa}$ for 7 days old samples, from $12.44 \mathrm{MPa}$ to $20.30 \mathrm{MPa}$ for 14 days old sample and from $14.83 \mathrm{MPa}$ to $24.8 \mathrm{MPa}$ for 56 days old samples, as presented in figure 12 .

Flexural strength test has been performed on $\mathrm{mm}$ samples by center point method according to the description above. Figure 13 presents the flexural strength differences between fly ash samples and fly ash with aggregates samples. The value difference for 7 and 28 days

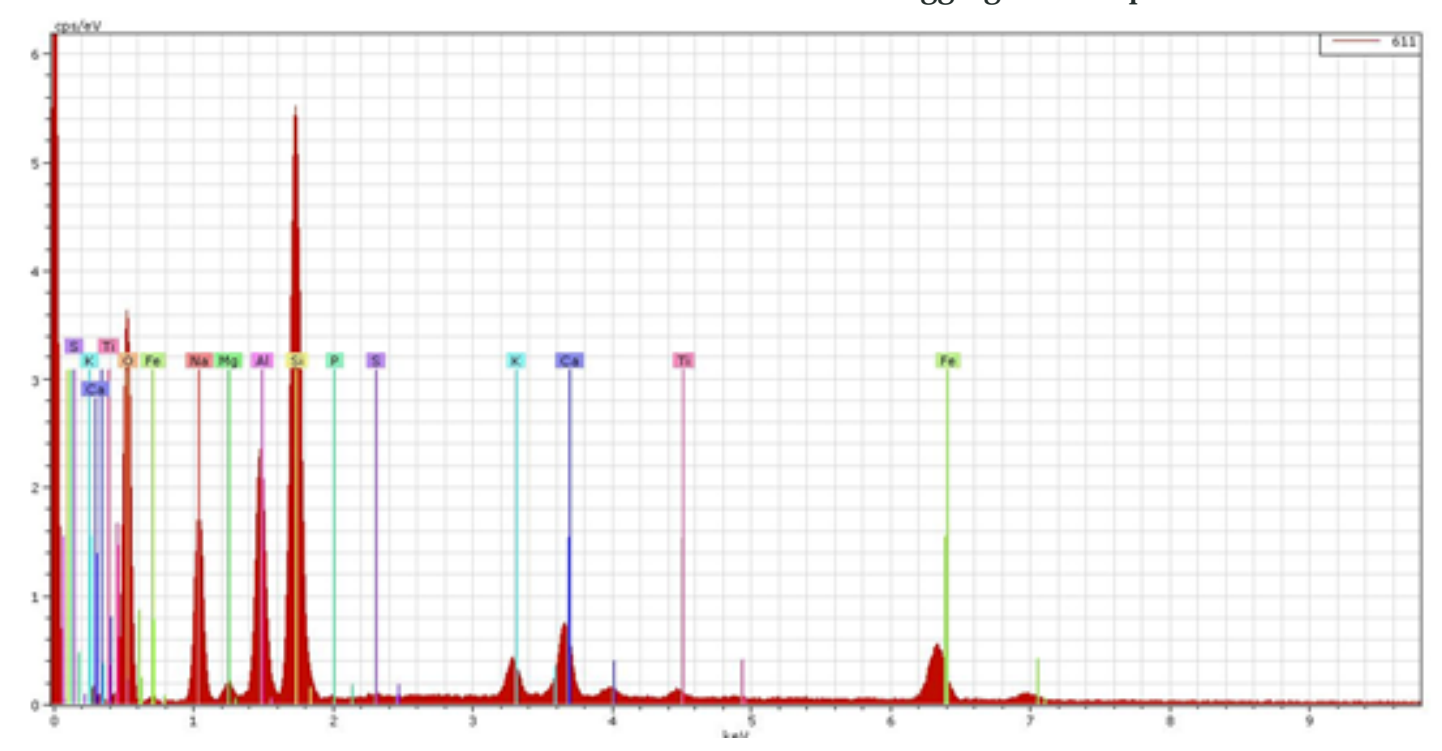

Fig. 8. EDS spectrum of fly ash based geopolymer sample
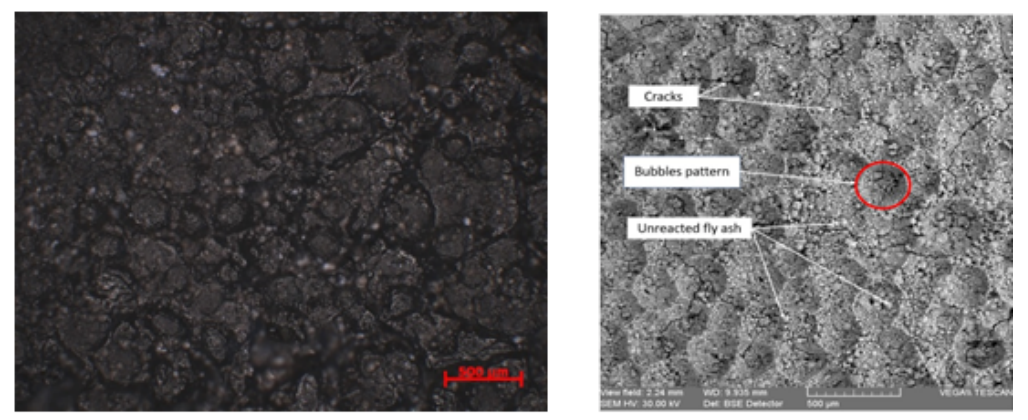

Fig. 9. Black layer microstructure: a) optical microstructure; b) SEM microstructure
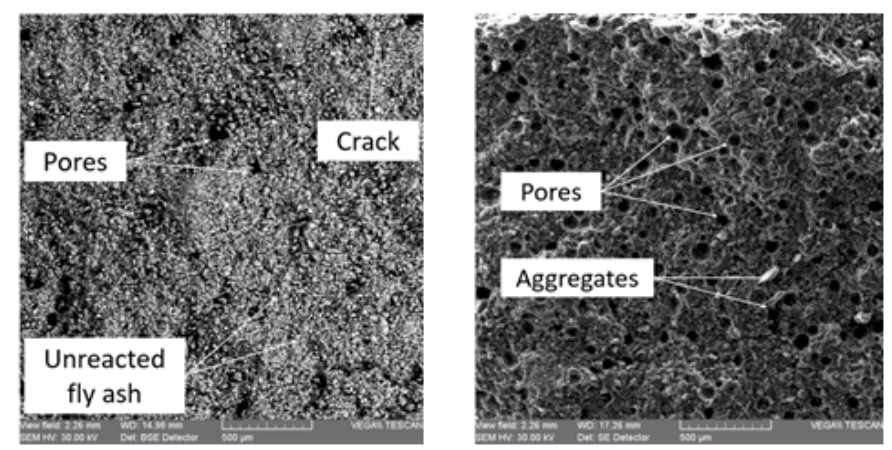

Fig. 10. SEM micrographs 100x: a) Fly ash samples; b) Fly ash and aggregates samples 

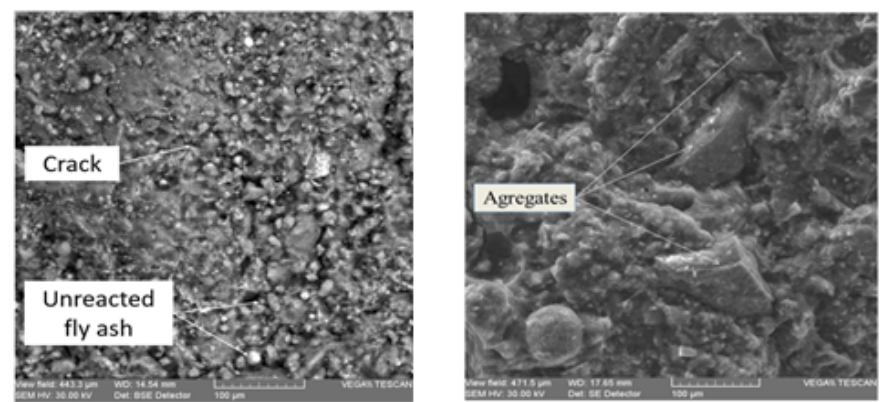

Fig. 11. SEM micrographs 500x: a) Fly ash samples; b) Fly ash and aggregates samples

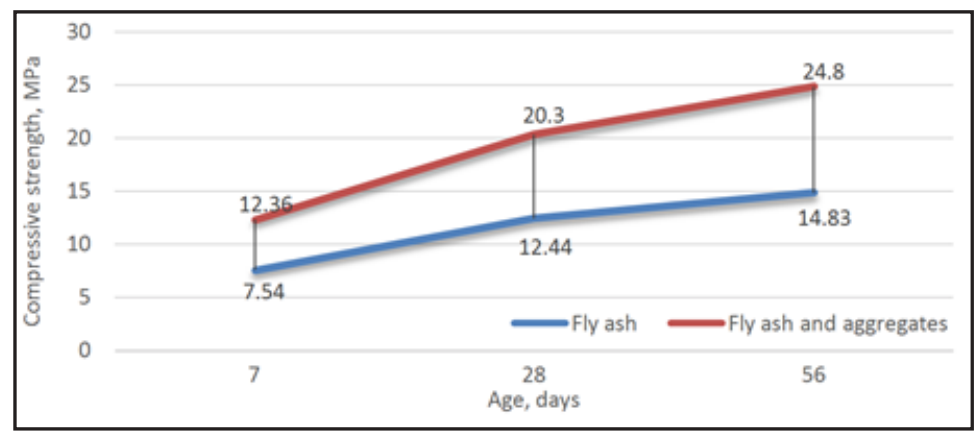

Fig. 12. Compressive strength of fly ash samples and fly ash and aggregates sample

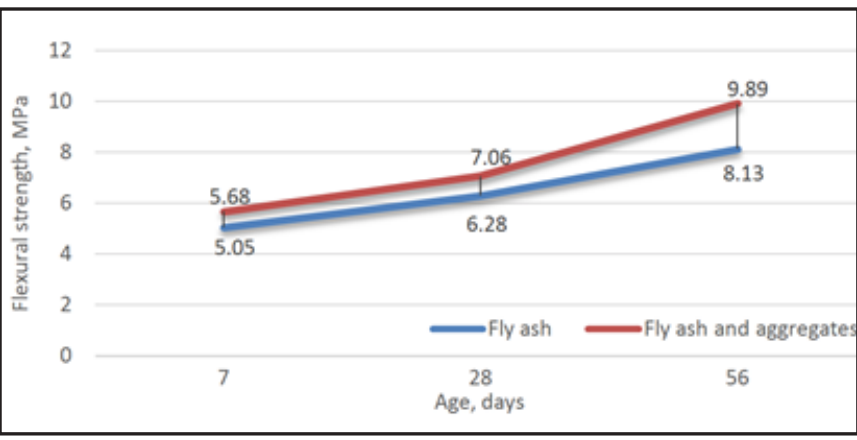

Sustainable Future, II, (SGEM 2014) Book Series: International Multidisciplinary Scientific GeoConference-SGEM, 2014, pp. 259-266. 3. BURDUHOS-NERGIS, D. D., ABDULLAH, M. M. A. B., VIZUREANU, P., TAHIR M. F. M., EUROINVENT ICIR 2018, Book Series: IOP Conference Series-Materials Science and Engineering, 2018, 374: DOI: 10.1088/ 1757-899X/374/1/012019.

4. LUHAR, S. U. K., International J ournal of Engineering Research and Applications, 5 (8), 2018, pp. 17-32.

5. BOUAISSI, A. LI L. Y., MOGA, L. M., SANDU, I. G., ABDULLAH, M. M. A., SANDU, A. V., Rev. Chim. (Bucharest), 69, no. 7, 2018, p. 1661-1667. 6. AHMAD, R., ABDULLAH, M. M. A. B., HUSSIN, K., SANDU, A. V., BINHUSSAIN, M., JAYA, N. A., Reviews on Advanced Materials Science,

Fig. 13. Flexural strength of fly ash samples and fly ash and aggregates sample

44 (1), 2016, pp. 26-32.

7. LUHAR, S., GOURAV, S., Journal of Civil Engineering Research, $\mathbf{5}$ (3), 2018, pp. 53-58.

old samples is lower than $1 \mathrm{MPa}(\approx 11 \%)$, at 56 days the difference is close to $1.5 \mathrm{MPa}(\approx 18 \%)$.

\section{Conclusions}

According to our study aggregates influence the structure, porosity and final properties of geopolymer samples.

Fly ash samples present large number of unreacted particles which acts as defects in samples structure, resulting in lower mechanical properties.

Flexural strength of fly ash with aggregates based geopolymers samples present higher values, for 7 and 28 days old samples the difference is lower than $1 \mathrm{MPa}(\approx 11 \%)$, but for 56 days the difference is close to $1.5 \mathrm{MPa}(\approx 18 \%)$.

Compressive strength test presence a major increase from 7.54 MPa to $12.36 \mathrm{MPa}$ for 7 days old samples, from $12.44 \mathrm{MPa}$ to $20.30 \mathrm{MPa}$ for 14 days old sample and from 14.83 MPa to 24.8 MPa for 56 days old samples.

Fly ash with $70 \%$ by mass aggregates presents porous structure higher density, close to $1.8 \mathrm{~g} / \mathrm{cm}^{3}$ and up to $60 \%$ higher compressive strength after 56 days compared to samples based on fly ash.

\section{References}

1. CASINI M., Advanced Materials and Nanotechnology to Improve Energy-Efficiency and Environmental Performance, Smart Buildings, 1st Edition, ISBN: 9780081006405, Woodhead Publishing, 2016. 2. CORBU, O., SZILAGYI, H., PUSKAS, A., POPOVICl, A., BAERA, C., MOGA, L., Conference: 14th International Multidisciplinary Scientific Geoconference (SGEM) Location: Albena, Bulgaria Date: Jun 17-26, 2014, Geoconference on Nano, Bio and Green - Technologies for a

8. YAHYA, Z., ABDULLAH, M. M. A., HUSSIN, K., ISMAIL, K. N., SANDU, A. V., VIZUREANU, P., ABD RAZAK, R., Rev. Chim. (Bucharest), 64 no. 12,2013, p. 1408-1412.

9. DAVIDOVITS J., Journal of Thermal Analysis and Calorimetry, 37, 1991, pp. 1633-56.

10. ABDULLAH, M. M. A. B., KAMARUDIN, H., BNHUSSAIN, M., KHAIRUL NIZAR, I., Journal of Asian Scientific Research, 1 (5), 2016, pp.247-253.

11. SZILAGYI, H., BAERA, C., CORBU, O., PUSKAS, A., Conference: 16th International Multidisciplinary Scientific Geoconference (SGEM 2016) Location: Albena, Bulgaria Date: J un 30-J ul 06, 2016, Nano, Bio and Green - Technologies for A Sustainable Future Conference Proceedings, Sgem 2016, Vol II Book Series: International Multidisciplinary Scientific GeoConference-SGEM, 2016, pp. 197-202. 12. LIEW Y. M., KAMARUDIN H., ABDULLAH M., M. A. B., LUQMAN M., NIZAR I. K., RUZAIDI C. M., Construction and Building Materials, 30, 2012, pp. 794-802.

13. BURDUHOS NERGIS, D. D., ABDULLAH, M. M. A. B., VIZUREANU, P., European J ournal of Materials Science, 2 (2), 2016, pp. 111-118.

14. YAHYA, Z., ABDULLAH, M. M. A. B., RAMLI, N. M., BURDUHOSNERGIS D. D., RAZAK A. B. D. R., EUROINVENT ICIR 2018, Book Series: IOP Conference Series-Materials Science and Engineering, 2018, 374: DOI: 10.1088/1757-899X/374/1/012068.

15. HE J., JIE Y., ZHANG J., YU Y., ZHANG G., Cement and Concrete Composites, 37, 2013, pp. 108-18.

16. NATH S. K., KUMAR S., Construction and Building Materials, 38, 2013, pp. 924-930.

17. KAMARUDIN, M. L., ABDULLAH M. M. A. B., MUSA M. M. M. A., NIZAR L., RUZAIDI K., HEAH C., Journal Construction and Building Materials, 30, 2011, pp. 794-802.

18. LUHAR, S. U. K., International Journal of Engineering Sciences and Emerging technologies, 8 (2), 2015, pp. 52-54.

Manuscript received: 17.10 .2018 